\title{
Stabilizing and reinforcing effects of different fibers on asphalt mortar performance
}

\author{
Meng-Meng Wu $\cdot$ Rui Li $\cdot$ Yu-Zhen Zhang $\cdot$ \\ Liang Fan $\cdot$ Yu-Chao Lv $\cdot$ Jian-Ming Wei
}

Received: 21 February 2014/Published online: 17 January 2015

(C) The Author(s) 2015. This article is published with open access at Springerlink.com

\begin{abstract}
Physical properties of different fibers (mineral, cellulose, or carbon fiber) and their stabilizing and reinforcing effects on asphalt mortar performance were studied. Scanning electron microscopy was used to study the effect of fiber's microstructure on asphalt mortar's performance. Laboratory tests of mesh-basket draindown and oven heating were designed and performed to evaluate the fibers' asphalt absorption and thermostability. A cone penetration test was used to study the flow resistance of fiber-modified asphalt mortar. Results showed that fiber can form a three-dimensional network structure in asphalt, and this network can be retained at high temperature. This network of fibers favors the formation of a thick coating of mastic without asphalt draining down. Cellulose fiber possessed a greater effect on asphalt absorption and stabilization than did the other fibers (mineral and carbon fiber). A dynamic shear rheometer was used to evaluate their rheological properties and rut resistance. Results indicated that fiber can effectively improve the rut and flow resistance of asphalt mortar. However, the bending beam rheometer results demonstrated that the addition of fiber had negative effects on the creep stiffness and creep rate of asphalt mortar.
\end{abstract}

Keywords Fiber - Asphalt mortar - SEM - Rheology · Mechanical properties

M.-M. Wu · R. Li · Y.-Z. Zhang (ه) · L. Fan · Y.-C. Lv J.-M. Wei

State Key Laboratory of Heavy Oil Processing, China University of Petroleum (East China), Qingdao 266555, Shandong, China e-mail: zhangyuzhen1959@163.com

Edited by Xiu-Qin Zhu

\section{Introduction}

Asphalt has been widely used for road pavement construction for centuries (Zhang et al. 2009; Wang et al. 2012). Because of its adhesive properties, asphalt has been primarily used as a binder for aggregate particles in asphaltconcrete (AC) mixture, a composite material used for constructing flexible highway pavements. However, AC pavements are subjected to damage from cracking and rutting (permanent deformation) under the effects of repeated vehicle loading and temperature cycling (Xu and Solaimanian 2008). Accordingly, different additives have been used to alter the phase composition and improve the engineering properties of asphalt matrix (Ahmedzade 2013). These additives primarily include organic polymers that have been extensively studied (Hao 2001; Cao and Ji 2011).

Recently, the application of fiber in asphalt modification has attracted many researchers. Experimental results have shown that fibers have better performance than polymers in reducing draindown of $\mathrm{AC}$ mixtures, and this is the reason why fibers are widely used in stone matrix asphalt and open-graded friction course (Hassan et al. 2005). In terms of efficiency, fiber-asphalt mixture shows a slight increase in the optimum asphalt binder content compared with the pure asphalt mixture. In this way, adding fibers to asphalt is very similar to the addition of very fine aggregates. Thus, fibers can stabilize asphalt to prevent leakage. This is due to the adsorption of asphalt on fibers (Tapkin et al. 2010; $\mathrm{Wu}$ et al. 2014). The reported results indicate that fiberasphalt mixtures have good moisture resistance, creep compliance, and rutting resistance, low-temperature anticracking properties, and durability (Tapkin et al. 2010). The mechanism of how fibers modify asphalt is complicated, yet the impact upon pavement performance is profound (Hassan et al. 2005). 
However, studies of the fiber-reinforcing mechanisms are rare, especially those based on physical properties, such as the stability and the microstructure of fiber. This paper aims to study the stabilizing and reinforcing mechanisms of different fiber-modified asphalt mortars. Several laboratory experiments were designed to study the physical properties of fibers and subsequently investigate fiber-reinforcing mechanisms. Softening point, cone penetration, dynamic modulus, and phase angle at high temperatures, as well as the creep stiffness of fiber-modified asphalt mortar at low temperatures were studied.

\section{Experimental}

\subsection{Experimental materials}

\subsubsection{Asphalt}

Straight-run asphalt binder (penetration grade pen-50), provided by the PetroChina Fuel Oil Company Limited (China), was chosen as the base asphalt in the present study. The main physical properties of pen-50 were determined according to the Traffic Industry StandardStandard Test Methods of Bitumen and Bituminous Mixtures for Highway Engineering (JTG E20-2011, China) and are shown in Table 1, including the thin-film oven test (TFOT) aging properties.

\subsubsection{Fibers}

Fibers are used to prevent asphalt binder draindown particularly for stone matrix asphalt and porous asphalt during the mixing, transportation, and compaction processes. Three kinds of fibers-mineral, cellulose, and carbon fiber-were used as modifier. The mineral fiber and cellulose fiber were supplied by the Jiangsu TianLong Continuous Basalt Fiber Hi-Tech Co. Ltd. (China), and the carbon fiber was produced by the Changzhou YueYang Friction Materials Co. Ltd. (China). The physical properties of the three types of fiber used are listed in Table 2.

\subsection{Experimental methods}

\subsubsection{Preparation of fiber-asphalt mortar}

The fibers were separately put into a $105^{\circ} \mathrm{C}$ oven for $24 \mathrm{~h}$ to ensure moisture-free surfaces, and solid asphalt $(600 \mathrm{~g})$ stored in a sealed can was preheated at $160{ }^{\circ} \mathrm{C}$ for $1 \mathrm{~h}$ to liquefy it for mixing. In order to investigate the effects of fibers on asphalt mortar, different fiber contents (i.e., 0,1 , 2 , and $3 \mathrm{wt} \%$ ) in the asphalt mortar were studied. The fiber content of $0 \mathrm{wt} \%$ represented pure asphalt mortar. The fiber was weighed and slowly added to the asphalt under stirring at $500 \mathrm{rpm}$ to prevent the fiber from possibly agglomerating. Then, they were mixed at $160{ }^{\circ} \mathrm{C}$ for approximately $30 \mathrm{~min}$ under stirring to produce homogeneous fiber-modified asphalt mortar. To avoid the adverse effect of excessive heat, the temperature was carefully monitored through thermocouple probe.

\subsubsection{Scanning electron microscopy (SEM)}

SEM (Hitachi S-4800, Japan) at an accelerating voltage of $5 \mathrm{kV}$ was used in this study for direct observation of fibers. Electron microscopy has been found to be preferable because it can provide a clear view of fibers in their initial state (Williams and Miknis 1998).

\subsubsection{Heating treatment in oven}

When mixed with $\mathrm{AC}$ mixture at high temperature, fibers will coalesce and some can even decompose. Hence, to evaluate the thermostability of fibers, a simple laboratory heating experiment was carried out with an XY oven (Wuxi Petroleum Asphalt Equipment Co. Ltd., China). A
Table 1 Physical properties of pen-50 base asphalt

\begin{tabular}{llll}
\hline Properties & \multicolumn{2}{l}{ JTG E20-2011 } & \multirow{2}{*}{ Measured values } \\
\cline { 2 - 3 } & Min & Max & \\
\hline Penetration $\left(25^{\circ} \mathrm{C}, 100 \mathrm{~g}, 5 \mathrm{~s}\right), 0.1 \mathrm{~mm}$ & 40 & 60 & 48 \\
Softening point, ${ }^{\circ} \mathrm{C}$ & 46 & - & 52.2 \\
Ductility $\left(10^{\circ} \mathrm{C}, 5 \mathrm{~cm} / \mathrm{min}\right), \mathrm{cm}$ & 10 & - & 11.8 \\
Ductility $\left(15{ }^{\circ} \mathrm{C}, 5 \mathrm{~cm} / \mathrm{min}\right), \mathrm{cm}$ & 80 & - & $>150$ \\
Viscosity $\left(60^{\circ} \mathrm{C}\right), \mathrm{Pa} \mathrm{s}$ & 200 & - & 492 \\
TFOT & & & \\
Mass change, $\%$ & \pm 0.8 & & 0.26 \\
Retained penetration, $\%$ & 60 & - & 71 \\
Ductility $\left(10{ }^{\circ} \mathrm{C}, 5 \mathrm{~cm} / \mathrm{min}\right), \mathrm{cm}$ & 2 & - & 5.6
\end{tabular}


Table 2 Basic physical properties of fibers (provided by manufactures)

\begin{tabular}{lllll}
\hline Fibers & Carbon fiber & Mineral fiber & Cellulose fiber & Specification \\
\hline Diameter, $\mu \mathrm{m}$ & $12-14$ & $13-16$ & $12-15$ & ASTM D2130 \\
Length, mm & $0.5-1.0$ & 6.0 & $0.5-2.0$ & ASTM D204 \\
Tensile strength, $\mathrm{MPa}$ & $/$ & $2,500-3,500$ & $100-300$ & ASTM D2256 \\
Density, $\mathrm{g} / \mathrm{cm}^{3}$ & $1.3-2.0$ & $2.65-3.05$ & $/$ & ASTM D3800 \\
Melting temperature, ${ }^{\circ} \mathrm{C}$ & 700 & 1,600 & $/$ & ASTM D276 \\
\hline
\end{tabular}

D2130: Standard Test Method for Diameter of Wool and Other Animal Fibers by Microprojection in American Society for Testing and Materials (ASTM)

D204: Standard Test Methods for Sewing Threads in ASTM

D3800: Standard Test Method for Density of High-Modulus Fibers in ASTM

D276: Standard Test Methods for Identification of Fibers in Textiles in ASTM

D2256: Standard Test Method for Tensile Properties of Yarns by the Single-Strand Method in ASTM

beaker with $100 \mathrm{~g}$ fiber was heated in an oven at $163{ }^{\circ} \mathrm{C}$ for $5 \mathrm{~h}$, which was similar to the construction temperature. The color, shape, and volume variations of fiber were recorded continually.

\subsubsection{Mesh-basket draindown experiment}

A mesh-basket draindown experiment was designed to evaluate adsorption and stabilization by fibers in asphalt binder. It is, described as follows: Ten percent of fiber (by mass) of asphalt binder (about $0.3 \mathrm{wt} \%$ fiber of AC mixture including aggregates) was utilized according to engineering practice. Then, a mixing sample ( $40 \mathrm{~g}$ ) was uniformly placed into the designed steel mesh-basket with a sieve size of $0.25 \mathrm{~mm}$, and maintained at $25^{\circ} \mathrm{C}$ for $2 \mathrm{~h}$. Afterward, the basket was heated in an environmental chamber under higher temperatures, and some asphalt binder would melt, flow, and drop out due to the heating effect. Two temperatures, 130 and $140{ }^{\circ} \mathrm{C}$, were used for all the fibers, while an additional temperature of $170{ }^{\circ} \mathrm{C}$ was applied for the cellulose fiber, since no obvious asphalt drops could be measured at lower temperatures. The sample was weighed at 30-min intervals, to determine the weight loss of asphalt binder. Lower weight loss and flowing of asphalt indicated the fiber's greater capacity to adsorb and stabilize asphalt.

\subsubsection{Softening point}

The softening point of asphalt mortar was obtained by means of a WSY-025D asphalt softening point tester equipped with a steel ball of $3.5 \mathrm{~g}$ and steel ring of $20 \mathrm{~mm}$ in diameter (Wuxi Petroleum Asphalt Equipment Co. Ltd., China). The sample was cooled in a water bath at $5{ }^{\circ} \mathrm{C}$ for $15 \mathrm{~min}$. Then, it was heated at a heating rate of $5{ }^{\circ} \mathrm{C} / \mathrm{min}$, and the softening point was taken at the temperature at which the mortar sample became soft enough to allow the ball to fall to a distance of $25.4 \mathrm{~mm}$. The softening point is also known as the ring-and-ball softening temperature $\left(T_{R \& B}\right)$.

\subsubsection{Cone penetration test}

The cone penetration of asphalt mortar was obtained using a WSY-026 penetration tester (Wuxi Petroleum Asphalt Equipment Co. Ltd., China). The cone penetration experiment was conducted to measure fiber-modified asphalt mortar resistance to flow and shear. Cone penetration is expressed in units of $0.1 \mathrm{~mm}$, the penetration depth of a standard cone under a $200 \mathrm{~g}$ load into the asphalt mortar sample after a 5-s loading time at a certain temperature. The prepared sample was kept at room temperature for 40 min until it was cooled and solidified, and then put in a water bath at $25{ }^{\circ} \mathrm{C}$ for more than $1 \mathrm{~h}$. Afterward, the sample was taken out from the water bath, and an iron cone was put on the sample surface. The cone would gradually penetrate into the asphalt mortar until it was stable without further sinking, and then, the sink depth was measured and recorded. It should be noted that the cone would not completely penetrate into the sample mixture.

\subsubsection{Rheological measurements}

The dynamic rheological properties of the fiber-modified asphalt mortar were measured using a dynamic shear rheometer (DSR, AR-500, Carri-Med Ltd., UK) over a wide range of temperatures (Tan et al. 2010). For tests at $64{ }^{\circ} \mathrm{C}$ and higher, two 25 -mm-diameter parallel plates with a 1-mm gap were selected to conduct the DSR measurement, as shown in Fig. 1. A sinusoidal strain was applied, and the strain was kept low enough so that all the tests were performed within the linear viscoelastic range. The actual strain and torque were measured for calculating various 
Fig. 1 Schematic representation of DSR measurement

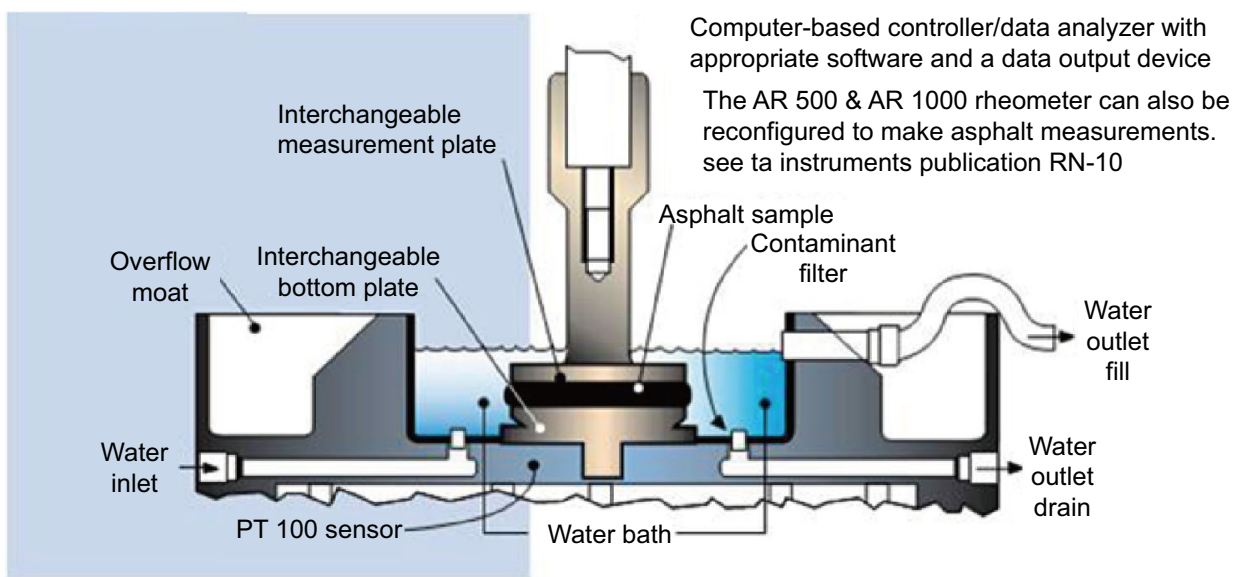

viscoelastic parameters, including complex modulus $\left(G^{*}\right)$ and phase angle $(\delta) . G^{*}$ is defined as the ratio of maximum shear stress to maximum strain, and it provides a measurement of the total resistance to deformation, which is the "sum" of the elastic part and viscous part of the mortar. The $\delta$ is the time lag between the applied stress and strain responses during a test, and it is a measure of the viscoelastic balance of the material behavior. In addition, the rutting factor $G^{*} / \sin \delta$ can be obtained to characterize the anti-deformation ability of the asphalt mortars according to the Strategic Highway Research Program (SHRP) specifications (USA) (Tan et al. 2010).

The low-temperature creep test was carried out to determine the low-temperature performance of the asphalt mortar using a bending beam rheometer (BBR, Cannon Instrument Company, Japan). In this test, the BBR sample beams $(125 \times 12.5 \times 6.25 \mathrm{~mm})$ were cooled in a methanol bath for $60 \mathrm{~min}$ at a constant temperature of $-6,-12$, -18 , and $-24{ }^{\circ} \mathrm{C}$, respectively. Then, the sample beam was placed on two stainless steel supports and loaded with $100 \mathrm{~g}$. The deflection was monitored with time and used for calculation of the stiffness as a function of time. The creep stiffness $(S)$ and the creep rate $(m)$ of the binders were determined at a loading time of $60 \mathrm{~s}$. The two parameters (creep stiffness and creep rate) were used as the low-temperature characteristics of the asphalt mortars (Hao et al. 2000).

\section{Results and discussion}

\subsection{Microstructure of fiber}

SEM images of the three fiber types are shown in Fig. 2. The cellulose fiber consists of ribbons, porous with a relatively flat cross section. Some cellulose filaments have been torn apart, resulting in an increase of surface area. The
$1.8 \mathrm{~m}^{2} / \mathrm{g}$ surface area of cellulose fiber was larger by $>10$ fold than that of the mineral and carbon fibers, which were only 0.13 and $0.05 \mathrm{~m}^{2} / \mathrm{g}$, respectively. These surface characteristics can explain the efficiency of cellulose fiber in binding greater amount of asphalt. The microstructures of mineral and carbon fibers were different from that of cellulose fiber since the cross sections of mineral and carbon fibers were quite round, with a smooth surface texture and a small surface area. In addition, the mineral fiber was more rigid than the flexible carbon fiber, and tended to be aligned with entanglement.

\subsection{Thermostability}

Thermal test results showed that the cellulose fiber was the most susceptible to coagulation, and it shrank noticeably at high temperature, while the other fibers showed no apparent change. It was noteworthy that the color of cellulose fiber changed from light gray to yellow during heating in the oven, and the carbon fiber became darker. However, the color of mineral fiber did not undergo any noticeable change. These results suggested that the cellulose fiber had the lowest thermostability, and the mineral fiber had the highest thermostability. This indicated that the mixing temperature was important for a specific fiber when used in asphalt mixture, or an appropriate fiber should be selected for a specific mixing temperature of AC material. It should be noted that in this study only a qualitative observation was performed, and more advanced test methods like differential scanning calorimetry (DSC) could be used to evaluate the thermostability quantitatively in future research.

\subsection{Adsorption and adhesion of asphalt}

Asphalt consists of asphaltenes, resins, aromatic hydrocarbons, and saturates (Morozov et al. 2004; Fritschy and 

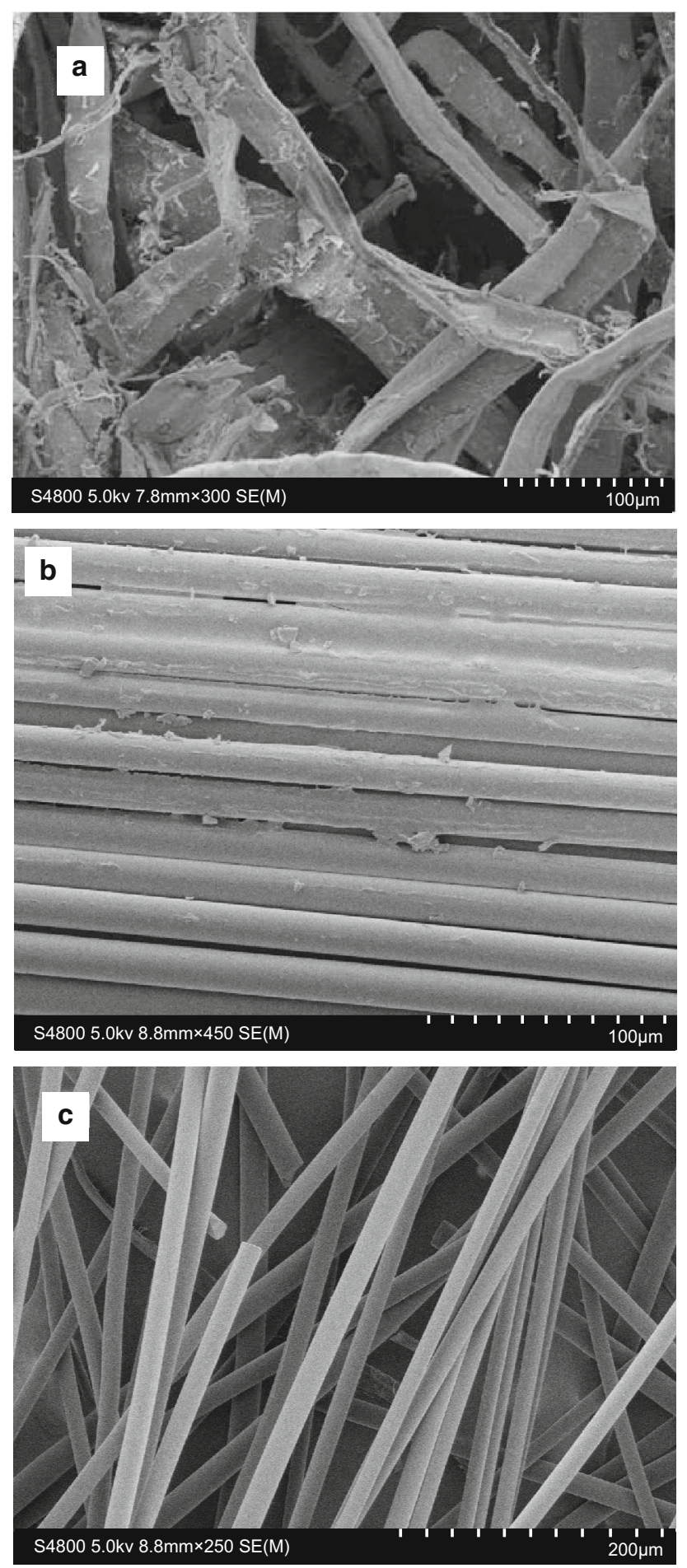

Fig. 2 SEM images of different fibers: a cellulose fiber; $\mathbf{b}$ mineral fiber; c carbon fiber

Papirer 1979). The fiber's adsorption of asphalt components can change the rheological behavior of the asphalt binder and the optimal asphalt content for the mixture design, and it will play a key role in the formation of the interface bonding between fiber and asphalt (Chen and Lin
2005). The mesh-basket draindown experiment results are presented in Table 3. It can be seen that cellulose fiber had the lowest asphalt drop and separation, that is to say, the highest asphalt adsorption and stabilization, followed by mineral fiber, and carbon fiber. This result should be attributed to their different specific surface areas and lengths. Compared with the cellulose fiber, the mineral fiber had a much lower adsorption and stabilization effect on asphalt, although it also had high specific surface area, mainly due to its smooth surface texture with a lubricant effect and low soaking effect. Although the carbon fiber had a relatively small specific surface area, it still had good effect on asphalt stabilization and great interface adhesion, because carbon fiber and asphalt are carbon-based products, so that carbon fiber has good adsorption of asphalt.

Interface strength is one of the primary factors determining fiber's reinforcing effect based on the mixing law of composite materials (Wo 2000). Fibers are uniformly dispersed in the asphalt, and their large surface areas could form an interface with asphalt. The acidic resin component in asphalt is a surface-active substance, and its adsorption onto the fiber's surface, and the physical and the chemical bond effects made some asphalt components be distributed as a monolayer on the fiber surface, forming a strongly binding "fiber-asphalt" interface layer. The adhesive property of the "fiber-asphalt" was stronger than that of the discrete asphalt outside of the interface layer, leading to an improvement of the asphalt mortar. The interfacial properties of fiber-modified asphalt depend on the molecular distribution, the chemical properties of the fiber, and the molecular structure and chemical composition of asphalt. The main role of the fiber-asphalt interface is to connect the two phases, and to pass and buffer the stress between them. The fiber-asphalt interface plays a key role in the physical and mechanical properties of fiber-modified asphalt mastic material. Damage to AC material can occur at the interface, such as the pullout of fiber from the asphalt binder, and shear slide at the aggregate surface. Fiber's adsorption of asphalt can increase asphalt's viscosity and

Table 3 Experimental results of mesh-basket draindown test (asphalt separation, \%)

\begin{tabular}{llllll}
\hline Temperature, ${ }^{\circ} \mathrm{C}$ & Fiber type & \multicolumn{4}{c}{ Asphalt separation, \% } \\
\cline { 3 - 6 } & & $30 \mathrm{~s}$ & $60 \mathrm{~s}$ & $90 \mathrm{~s}$ & $120 \mathrm{~s}$ \\
\hline 130 & Carbon fiber & 3.5 & 7.4 & 8.7 & 9.5 \\
& Mineral fiber & 1.7 & 4.6 & 5.7 & 6.3 \\
& Cellulose fiber & 0 & 0 & 0 & 0 \\
140 & Carbon fiber & 11.1 & 12.6 & 13.1 & 14.0 \\
& Mineral fiber & 7.3 & 8.0 & 8.2 & 8.8 \\
\multirow{2}{*}{170} & Cellulose fiber & 0 & 0 & 0 & 0 \\
\hline
\end{tabular}


improve interface adhesion between asphalt and fiber or aggregate. Moreover, the increased fiber-asphalt interface adhesion improves the anti-cracking strength of AC mixture (Putman and Amirkhanian 2004).

\subsection{Softening point}

The ring-and-ball softening point $\left(T_{\mathrm{R} \& \mathrm{~B}}\right)$ is another important performance criterion for asphalt mortars. The $T_{\mathrm{R} \& \mathrm{~B}}$ increased rapidly with the addition of fibers as shown in Fig. 3. It was also found that the softening point eventually increased in the following order: carbon fiber $<$ cellulose fiber $<$ mineral fiber. As the softening point is used to evaluate asphalt's resistance to flow and deformation, the present results indicated that the addition of fiber to asphalt mortar increases resistance to flow and deformation. Mineral fiber-modified asphalt mortar showed the strongest resistance, followed by cellulose fiber-modified asphalt mortar, and carbon fiber-modified asphalt mortar showed the weakest resistance. The increase in $T_{R \& B}$ was related to fiber length and content (Chen and Lin 2005). The maximum temperature of road pavements is approximately $60{ }^{\circ} \mathrm{C}$ in summer; hence, the fiber content needs to be at least $1.0 \mathrm{wt} \%$ by mortar weight for cellulose and mineral fibers, and $2 \%$ for carbon fibers, to ease the effect of hot summer temperatures.

Mineral fiber-modified asphalt mortar has a higher softening point than the other two fiber-modified asphalt mortars because of its fiber entanglement. In the cone penetration test, similar results were obtained for $T_{\mathrm{R} \& \mathrm{~B}}$, as shown in Fig. 4. It was found that cellulose and carbon fibers had the same fiber length, but resulted in completely different softening points and cone penetrations (cone sink depth). The reason may be that carbon fibers cannot become entangled with each other.

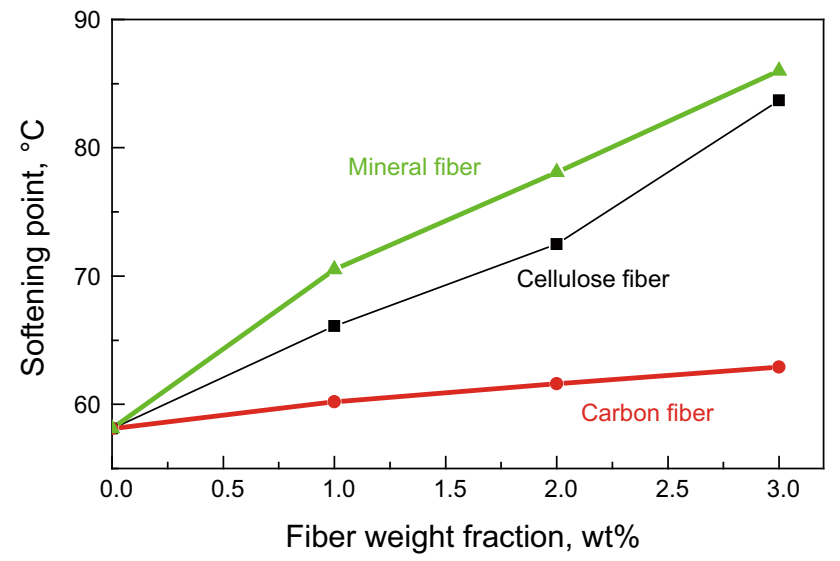

Fig. 3 Softening point of fiber-modified asphalt mortars

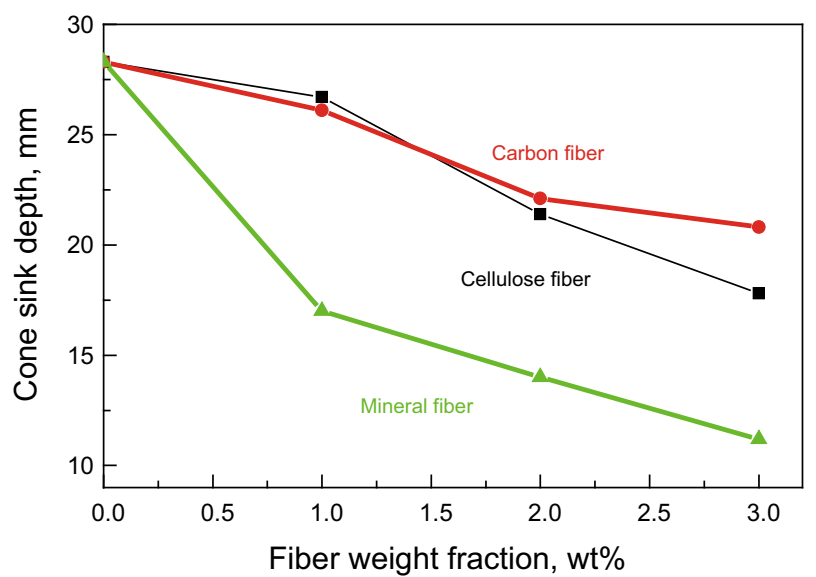

Fig. 4 Cone penetration of fiber-modified asphalt mortar

\subsection{Cone penetration test}

Based on the force balance, the shear stress of fiber-modified asphalt mortar at the direction tangential to the cone surface can be determined as follows:

$\tau=\left[G \cos ^{2}(\alpha / 2)\right] /\left[\pi h^{2} \tan (\alpha / 2)\right]$

where $G$ is the cone weight ( $1.025 \mathrm{kN}), h$ is the sink depth $(\mathrm{m})$, and $\alpha$ is the cone angle $\left(30^{\circ}\right)$. For each fiber, experiments were repeated twice. Here the cone penetration and the calculated shear stress according to the force balance were used to evaluate fiber-modified asphalt mortar resistance to flow and deformation, and they are presented in Table 4. It can be seen that all the fiber-modified asphalt mortars exhibited a significant decrease in cone sink depth and increase in shear stress. The cone penetration of fibermodified asphalt mortar decreased in the order (or increased in the order for shear stress) as follows: cellulose fiber, carbon fiber, and mineral fiber.

These experimental results are explained as follows: fibers are dispersed in the asphalt, and the asphalt is adsorbed over the fiber's surface as a monolayer, forming a strong binding force between the "fiber-asphalt" interfacial layer and three-dimensional spatial network. This network can be retained at high temperature, resulting in the formation of a thick mastic coating without asphalt draining down (Wiljanen 2003). The mineral fiber had the

Table 4 Cone penetration and shear stress of fiber-modified asphalt mortar

\begin{tabular}{lllll}
\hline Items & $\begin{array}{l}\text { Asphalt } \\
\text { mortar }\end{array}$ & $\begin{array}{l}\text { Carbon } \\
\text { fiber }\end{array}$ & $\begin{array}{l}\text { Mineral } \\
\text { fiber }\end{array}$ & $\begin{array}{l}\text { Cellulose } \\
\text { fiber }\end{array}$ \\
\hline Fiber fraction, wt\% & 0 & 1 & 1 & 1 \\
Cone sink depth, mm & 2.83 & 2.61 & 1.70 & 2.67 \\
Shear stress, MPa & 141 & 166 & 393 & 159 \\
\hline
\end{tabular}


greatest effect on reducing the cone sink depth and improving the shear stress among these three fibers, due to its great networking structure. Moreover, fibers can absorb the light components in asphalt and increase the viscosity of asphalt mortar; therefore, fiber increases the shear strength of asphalt mortar. In addition, the fiber has high tensile strength which can hold asphalt and resist flowing and crack propagation more effectively (Li 1992).

\subsection{Viscoelastic behavior}

The viscoelastic behavior of the samples was characterized by complex modulus $\left(G^{*}\right)$ and phase angle $(\delta)$ of asphalt binder measured with DSR. $G^{*}$ is a measurement of the overall resistance of a material to deformation, while $\delta$ is a measurement of the viscoelastic characteristics (Tan et al. 2010). Figure 5 shows the curves of $G^{*}$ and $\delta$ versus temperature for fiber-asphalt mortars, respectively. $G^{*}$ decreased, whereas $\delta$ increased with the increasing temperature, indicating that the mortars lose their elastic property and behave more like a liquid at high temperature. In addition, $\delta$ was always higher than $45^{\circ}$, indicating that the loss modulus $\left(G^{\prime \prime}=G^{*} \sin \delta\right)$ was higher than the storage modulus $\left(\mathrm{G}^{\prime}=G^{*} \cos \delta\right)$ within the range of testing temperatures.

According to the SHRP specification, the rutting factor, $G^{*} / \sin \delta$, was used to measure the contribution of asphalt binder to rutting performance (Tan et al. 2010). Higher $G^{*}$ / $\sin \delta$ indicated higher rutting resistance of asphalt-fiber mixture. Therefore, much greater attention was given to this parameter than other parameters. Figure 6 presents the rutting factors of three fiber-modified mortars at different testing temperatures. Regardless of the testing temperatures, the $G^{*} / \sin \delta$ was improved with the addition of fiber, indicating the fiber-modified asphalt mortars had improved permanent deformation resistance at high temperature. The cellulose fiber-modified asphalt mortar had the highest $G^{*} /$ $\sin \delta$, which was attributed to its highest absorption of light

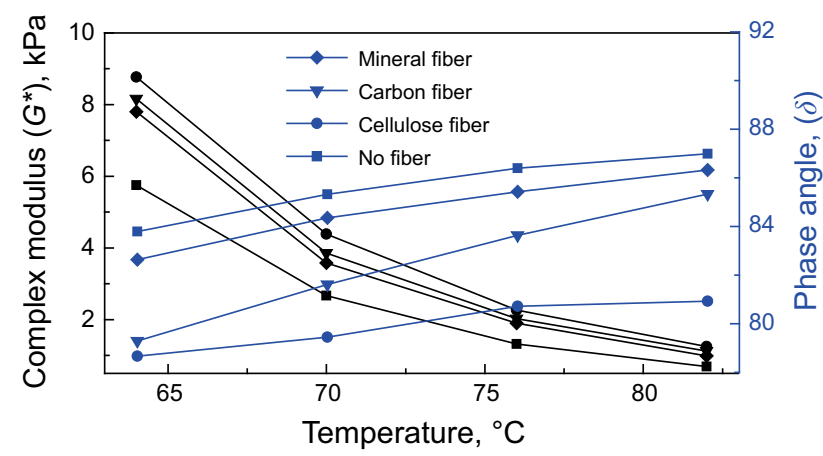

Fig. 5 The complex modulus $\left(G^{*}\right)$ and phase angle $(\delta)$ of different fiber-modified asphalt mortars

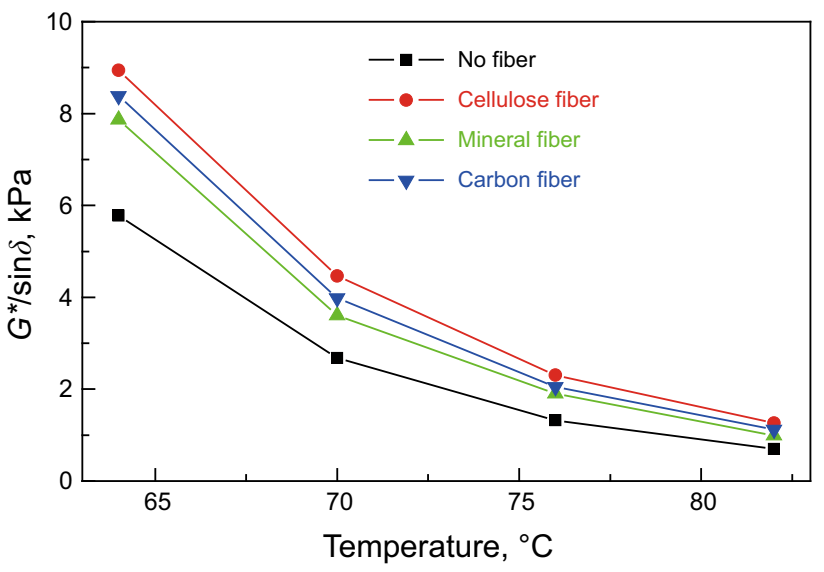

Fig. 6 Rutting factors of different fiber-modified asphalt mortars

components in asphalt to improve the stiffness. The mineral fiber-modified asphalt mortar had the lowest $G^{*} / \sin \delta$, which was attributed to its smooth surface texture, although it had a relatively larger specific surface area. It can also be seen that the $G^{*} / \sin \delta$ of the fiber-modified asphalt mortars decreased with the increasing temperature. As higher $G^{*} /$ $\sin \delta$ represented better high-temperature performance, the rutting resistance of asphalt mortar decreased when temperature rose. In addition, $G^{*} / \sin \delta$ eventually increased in the following order of pure asphalt mortar $<$ mineral fibermodified asphalt mortar $<$ carbon fiber-modified asphalt mortar $<$ cellulose fiber-modified asphalt mortar. The results of the present study showed that the addition of fiber increases $G^{*} / \sin \delta$ for the asphalt mortar, that is to say, the temperature sensitivity decreases.

The low-temperature creep stiffness $(S)$ and creep rate $(m)$ for fiber-modified asphalt mortars were determined using the BBR at four different temperatures, and the result is shown in Fig. 7. It can be seen that the stiffness $(S)$ of asphalt mortar increased with the addition of fibers, indicating that the addition of fibers increased the cracking potential of the asphalt mortars, thereby having a negative effect on the cracking resistance. For $m$-value, although there were some variations, the whole trend was that $m$ value was reduced with the addition of fibers. It is well known that the higher the creep rate $(m)$, the quicker the stress could be released, and hence the better the cracking resistance of the asphalt mortars. So, increasing the temperature would improve the cracking resistance of asphalt mortar, and this was in accordance with the low-temperature creep stiffness analysis. However, it has been reported that asphalt mixtures containing fiber have good low-temperature properties in terms of low-temperature flexural tests (Tapkin et al. 2010). Hence, more research needs to be pursued to investigate the effect of fiber on the low-temperature performance of asphalt mixtures. 


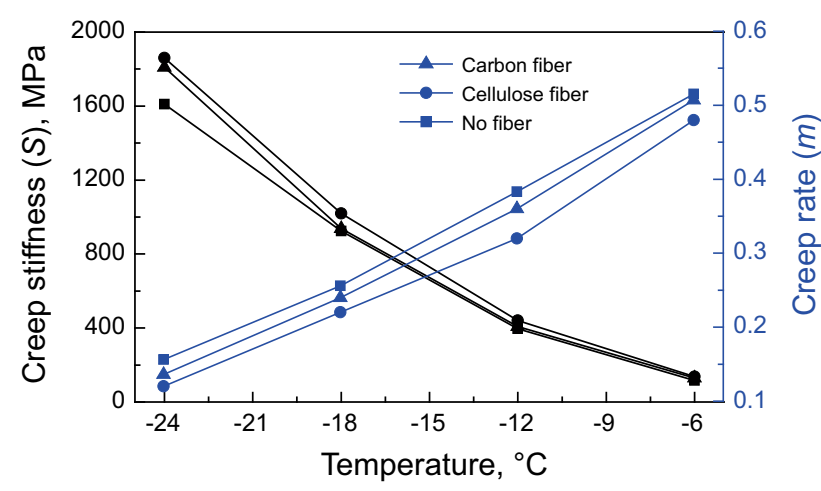

Fig. 7 The creep stiffness $(S)$ and creep rate $(m)$ of fiber-modified asphalt mortars

\section{Conclusions}

A comprehensive laboratory investigation was carried out to study the reinforcement effects of three kinds of fibers on asphalt mortars and their mechanisms, and the following results were obtained.

Fibers are dispersed in the asphalt, and some asphalt components are adsorbed over the fiber's surface as a monolayer, forming a strong binding force "fiber-asphalt" interface layer and three-dimensional spatial networks. Fibers can reinforce asphalt mortar through a spatial network and the reinforcing effects also depended on the fiber's structures and properties including shape, size and tensile strength. Due to its larger specific surface area, cellulose fiber showed more asphalt absorption than the other two fibers. The cone penetration experiment showed that all fiber-asphalt mortars present pronouncedly decreased sink depth while showing the increasing shear stress. The DSR tests showed that fiber-modified asphalt mortars have larger complex shear modulus $\left(G^{*}\right)$ and rutting parameters $\left(G^{*} / \sin \delta\right)$, and have smaller phase angle $(\delta)$ compared with the pure asphalt mortar used in this study. Hence it can be noted that fibers considerably improved asphalt mortar rutting resistance and resistance to flow. However, fibers had a negative effect on the creep stiffness and creep rate of the asphalt mortar. Our future efforts will be to perform mechanical testing focusing on fatigue, static and repeated creeps, and wheel tracking tests to further characterize the asphalt mixtures made by fiber-modified asphalt mortars discussed in this paper.

Acknowledgments The work is supported by the National Natural Science Foundation of China (51008307), the Fundamental Research Funds for the Central Universities (09CX04039A), and the Graduate Student Innovation Project of China University of Petroleum (East China) (12CX06055A).
Open Access This article is distributed under the terms of the Creative Commons Attribution License which permits any use, distribution, and reproduction in any medium, provided the original author(s) and the source are credited.

\section{References}

Ahmedzade P. The investigation and comparison effects of SBS and SBS with new reactive terpolymer on the rheological properties of bitumen. Constr Build Mater. 2013;38:285-91.

Cao DW, Ji J. Evaluation of the long-term properties of sasobit modified asphalt. Int $\mathbf{J}$ Pavement Res Technol. 2011;4(6): 384-91.

Chen JS, Lin KY. Mechanism and behavior of bitumen strength reinforcement using fibers. J Mater Sci. 2005;40:87-95.

Fritschy G, Papirer E. Dynamic-mechanical properties of a bitumensilica composite. Rheol Acta. 1979;18(6):749-55.

Hao PW. Study on compatibility between SBS modifier and asphalt. Pet Process Petrochem. 2001;32(3):54-6.

Hao PW, Zhang DL, Hu XN. Evaluation method for low temperature anti-cracking performance of asphalt mixture. J Xi' an Highway Univ. 2000;20(3):1-5.

Hassan HF, Oraimi SA, Taha R. Evaluation of open-graded friction course mixtures containing cellulose fibers and styrene butadiene rubber polymer. J Mater Civil Eng. 2005;17(4):415-22.

Li VC. Postcrack scaling relations for fiber reinforced cementitious composites. J Mater Civil Eng. 1992;4(1):41-57.

Morozov V, Starov D, Shakhova N, et al. Production of paving asphalts from high-wax crude oils. Chem Tech Fuels Oil. 2004;40(6):382-8.

Putman BJ, Amirkhanian SN. Utilization of waste fibers in stone matrix asphalt mixtures. Resour Conserv Recycl. 2004;42(3): 265-74.

Tan YQ, Li XL, Zhou XY. Interactions of Granite and Asphalt Based on the Rheological Characteristics. J Mater Civil Eng. 2010;22(8):820-5.

Tapkin S, Çevik A, Uşar Ü. Prediction of Marshall test results for polypropylene modified dense bituminous mixtures using neural networks. Expert Syst Appl. 2010;37:4660-70.

Wang HN, You ZP, Mills-Beale J, et al. Laboratory evaluation on high temperature viscosity and low temperature stiffness of asphalt binder with high percent scrap tire rubber. Constr Build Mater. 2012;26:583-90.

Wiljanen BR. The pavement performance and life-cycle cost impacts of carbon fiber modified hot mix asphalt, MS Thesis, Michigan Technological University. 2003.

Williams TM, Miknis FP. Use of environmental SEM to study asphalt-water interactions. J Mater Civil Eng. 1998;10(2):121-4.

Wo D. Comprehensive composite materials. Beijing: Chemistry Industry Press; 2000.

Wu MM, Li R, Zhang YZ, et al. Reinforcement effect of fiber and deoiled asphalt on high viscosity rubber/SBS modified asphalt mortar. Pet Sci. 2014;11:454-9.

$\mathrm{Xu}$ Q, Solaimanian M. Measurement and evaluation of asphalt thermal expansion and contraction. J Test Evaluat. 2008;36:1-6.

Zhang BC, Xi M, Zhang DW, et al. The effect of styrene-butadienerubber/montmorillonite modification on the characteristics and properties of asphalt. Constr Build Mater. 2009;23:3112-7. 